\title{
SINGLE LATERAL PLATE VERSUS DOUBLE PLATING OF COMMINUTED SUPRACONDYLAR FEMORAL FRACTURES
}

By

\begin{abstract}
Ahmed Mohammed Abd El-Noor Saad, Ahmed Abd El-Hamid Shamma, and Mohammed Ali El-Marghany
\end{abstract}

Department of Orthopedic Surgery, Faculty of Medicine, Al-Azhar University, Egypt

Corresponding author Name: Ahmed Mohammed Abd El-Noor Saad

Mobile: +201093062779, E-mail: ahmed.elfiky33@yahoo.com

\begin{abstract}
Background: Fractures of the distal femur are rare and severe. For an extra-articular fracture, all therapeutic options are possible and mini-invasive surgery can be performed. In case of an intra-articular fracture, open reduction and internal plate fixation should be performed.

Objective: To evaluate the functional and radiological outcomes of 20 patients with comminuted supracondylar fractures managed by either single or double plating.

Patients and Methods: A prospective randomized clinical study was done in the period between November 2019 and September 2020 involving 20 cases with distal femoral fractures. All patients were operated at AlAzhar University Hospitals and Al-Helal Hospital. Patients were divided into two groups/ preoperatively. The patients were randomly allocated for treatment with either: Group I managed by single lateral plate ,or group II managed by double plating.

Results: There were insignificant differences between the two groups regarding range of movement, pain, knee society score and complications.

Conclusion: Although both lateral and double plating fixation using dual approach for type C2 and C3 distal femoral fractures were efficient and safe methods of management, double plating recommended in these cases, i.e. medial supracondylar bone loss, low transcondylar bicondylar fracture, medial Hoffa fracture, per prosthetic distal femur fractures, nonunion after failed fixation with single lateral plate, poor bone quality and comminuted distal femur fractures $\mathrm{C} 3$.
\end{abstract}

Keywords: Supracondylar femoral fractures, lateral locking plate, double plating.

\section{INTRODUCTION}

Fractures of the distal femur are rare and severe. The estimated frequency is $0.4 \%$ of all fractures and $3 \%$ of femoral fractures (Elose et al., 2018). A classic bimodal distribution is found with a peak in frequency in young men (in their 30s) and elderly women (in their 70s). The usual context is a high energy trauma in a young patient and a domestic accident in an elderly person (Elose et al., 2018). The gender ratio has changed and today there is a majority of women ( $1 \mathrm{man} / 2$ women). Sufficient stabilization to withstand static loading forces on bone and dynamic muscular forces can only be obtained with surgery. An orthopedic treatment is rare: it is proposed in bedridden patients and/or in patients with reduced autonomy in 
fractures with little or no displacement (Elose et al., 2018). Distal femoral fractures are classified according to $\mathrm{AO}$ classification into (A, B, C) A type is simple extra articular fracture, B type is partial articular and $\mathrm{C}$ type is completely intra articular and each of them is sub classified in 1, 2, 3 according to the pattern of the fracture (Meinberg et al., 2018). For an extra-articular fracture, all therapeutic options are possible and miniinvasive surgery can be performed. In case of an intra-articular fracture, open reduction and internal plate fixation should be performed with the patient on a standard operating table (Steinberg et al., 2017). External fixation is indicated for local monitoring of an open fracture and in case of associated vascular injury, the fracture must be stabilized rapidly. Three main problems are commonly observed in these fracture; First, adequate exposure of articular surface, particularly of medial femorl condyle and coronal plane fractures is exhausting. Second, the standard implants used for other types of distal femoral fracture such as the condylar nails are not helpful for articular surface reduction and fixation (Khalil et al., 2012). Third, in setting of medial commination and short distal segment, there is high incidence of loss of fixation and varus collapse (Imam et al., 2018). Double plating: double plating is complete and anatomical reconstruction of these severe injuries, facilitation of preliminary $\mathrm{k}$-wire fixation from all directions around the distal end of femur, comfortable application of the medial plate, ideal fixation of medial and lateral Hoffa fractures, complete grafting of bony defects at all locations with good impaction, addressing associated internal knee derangement whenever possible, lower incidence of suprapatellar area adhesions, and uncomplicated wound healing (Zhang et al., 2018). The norm has been surgical management for these fractures, encouraging early joint motion and avoiding joint stiffness (Gwathmey et al., 2010).

Unfortunately, there is no less evidence in the literature of problems such as loss of alignment, delayed/ non-union, and implant failure (Henderson et al., 2011). Some reports, focused on comminuted Ctype fractures, suggest that better recovery may result from double plating. There is, however, no literature on the outcome distinction between single lateral plate and double plating in comminuted A- or Ctype fractures (Khalil et al., 2012).

The present work aimed to evaluate the functional and radiological outcomes of 20 patients with comminuted supracondylar fractures managed by either single or double plating.

\section{PATIENTS AND METHODS}

The current study was conducted as a prospective randomized-controlled trial at Al-Azhar University Hospitals and AlHelal Hospital during the period from November 2019 to September 2020 including 20 cases with types C2 and C3 distal femoral fractures, and a follow up period of 6 months. Ethical approval was obtained prior to the initiation of the study. All fulfilled our selection criteria of both genders, above the age of 18 years, presenting with types $\mathrm{A} 2, \mathrm{~A} 3, \mathrm{C} 2$ and $\mathrm{C} 3$ distal femoral fractures, with no absolute medical contraindications to surgery, without associated neurovascular compromise prior to surgery. Patients with 
preoperative neuromuscular compromise in the symptomatic extremity, and those presenting with other types of distal femoral fractures or pathological fractures were excluded. The patients were divided into two equal groups: Group I were managed with single lateral plate, and Group II were managed with double plating.

All displaced supracondylar fractures were admitted, and injured distal femur was immobilized in splint with knee in 5 to 20 degrees of flexion. Elevation and ice compression were advised. Surgery was planned and technique was selected according to random number generated by computer, and was enveloped securely so as to be opened at surgery time. All patients were operated under spinal anesthesia.

Surgical techniques were the principles of management to achieve anatomical articular reduction and preserve the blood supply while providing rigid stable fixation that was strong enough to withstand early functional mobilization. After anatomical reduction of the condyles with lag screws, fixation of the condyles to the shaft with either:

\section{Group I: Single lateral plate (Fig 1)}

It was done through lateral approach and fixation using lateral locked distal femoral plate. The placement of locked cancellous bone screws into the distal portion of the lateral locked plate was highly variable and based on the pattern of the fracture, the location of the lag-screws, and the adequacy of the bone stock. At least, three screws were placed into the condyles, and more were placed if technically feasible. After fixation of the locked plate to the proximal and distal fragments, stability was tested intraoperative.

\section{Group II: Double plating technique} (Fig 2)

It was done through dual separate approach (medial and lateral) and fixation is done using lateral locked distal femoral plate and medial buttress plate. A medial plate was applied through separate medial approach. At least two cancellous screws were used distally and two cortical screws were used proximally for fixation of the medial plate. The operative approach that was used for the medial plating consisted of a longitudinal ten to fifteen-centimeter incision, extending from a point five centimeters distal to the adductor tubercle up to the medial aspect of the thigh. The medial cortex of the femur was exposed by dissection of the plane anterior to the adductor magnus and posterior to the vastus medialis. The geniculate arteries were identified and were ligated as necessary. Because the dissection was anterior to the adductor canal and always remained distal to the mid-part of the thigh, the superficial femoral artery was not encountered. 


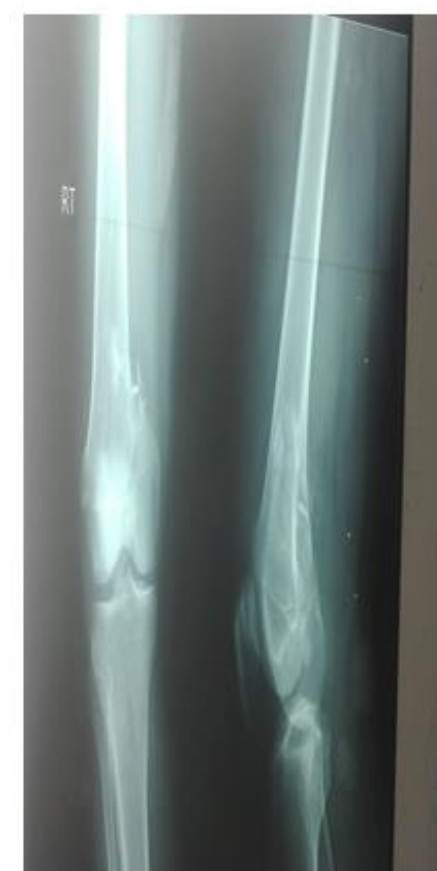

(A)

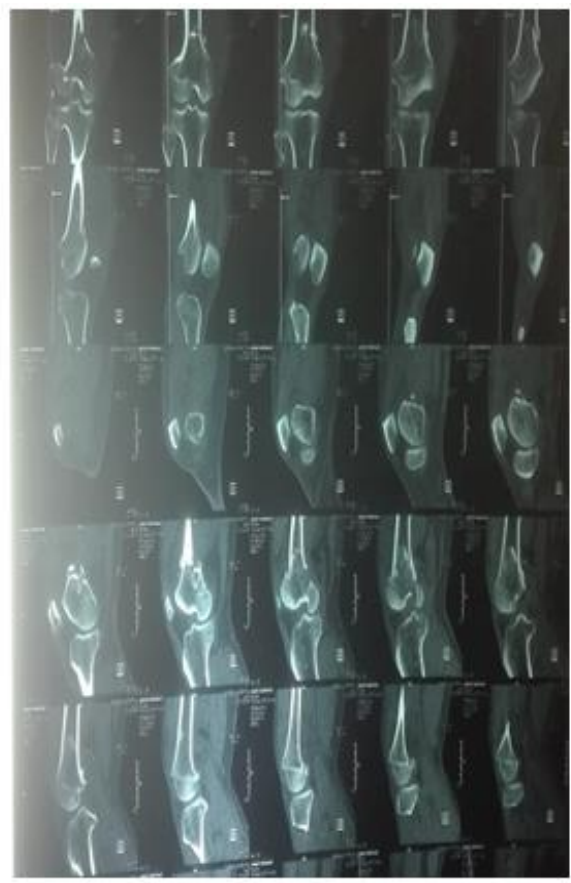

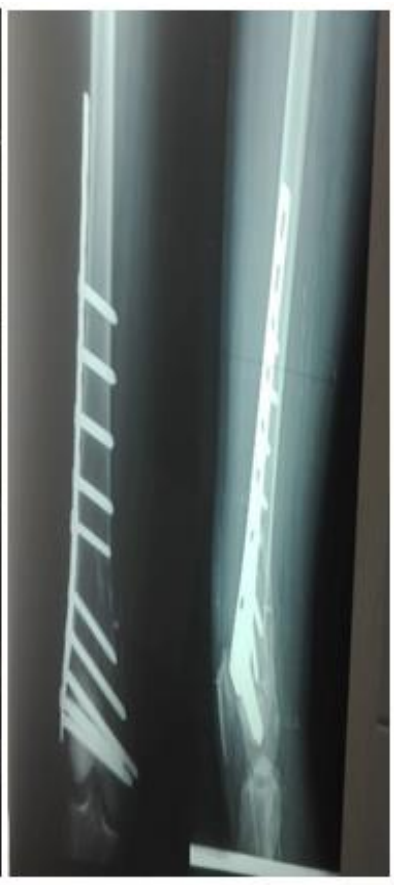

(B)

Figure (1): Male patient 40 years old with right supracondylar femur fracture type A2, single lateral technique (a) preoperative $x$-ray\& $C T$, (b) postoperative x-ray

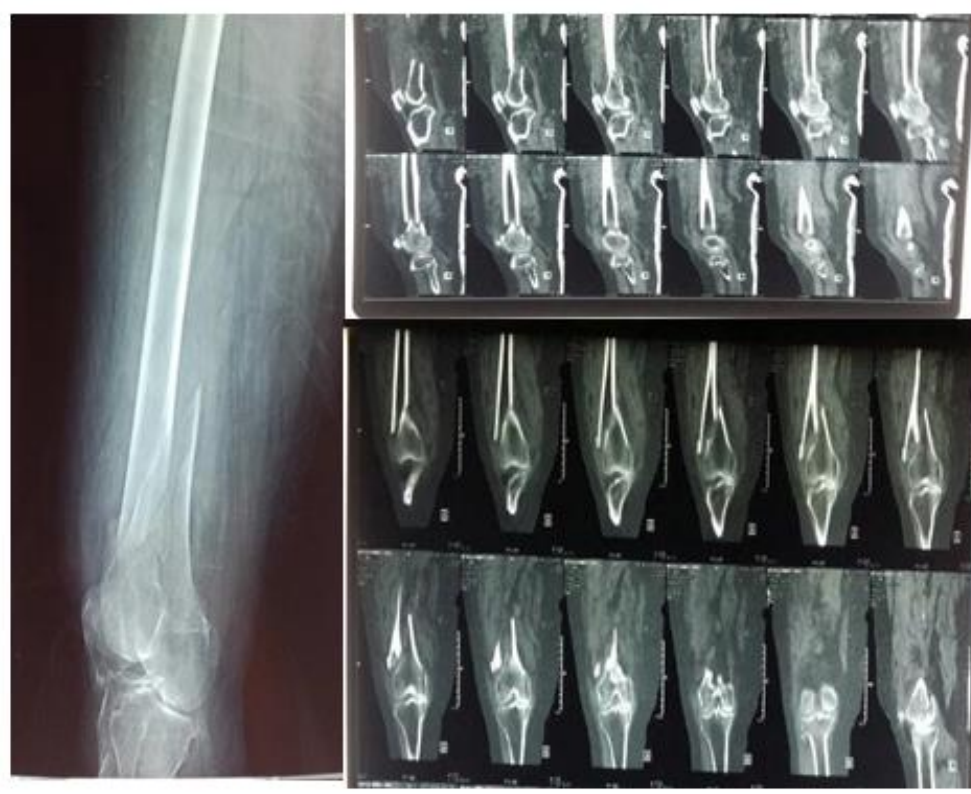

(A)

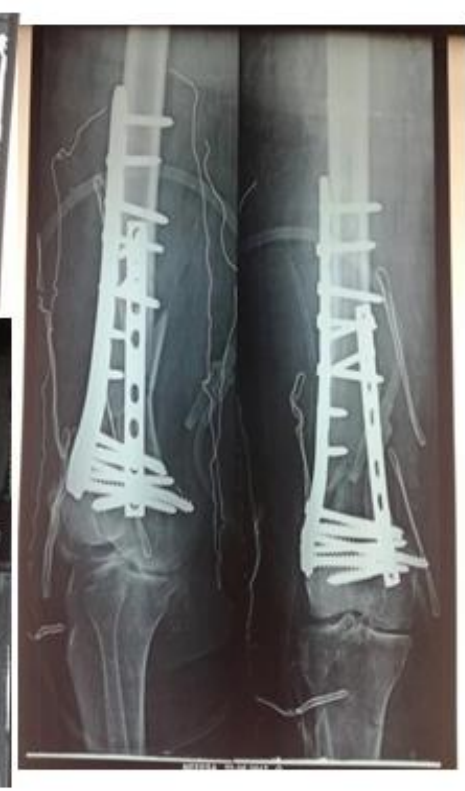

(B)

Figure (2): Female patient 53 years old with right supracondylar femur fracture C2, double plating technique (a) preoperative $x$-ray \&CT, (b) postoperative $x$ ray 
Postoperatively, the limb was placed in an above knee brace with knee-hinges. The range of motion started at 30 degrees and was then advanced on a daily basis. The patients were followed up for at least six months. Every two weeks for the first month, then every month thereafter. Every time the patient was examined clinically and radio logically and encouraged to continue active exercises to reach normal range of motion and to resume the activity again.

Assessment was done using The Knee Society Score which evaluates the clinical profile with regards to pain intensity, range of motion and stability in the anteroposterior and mediolateral planes, flexion deformities, contractures and poor alignment.

Knee society score (100 Points Total)

Pain

- None 50
- Mild, occasional.................45

- Mild (stairs only)...............40

- Mild walking and stairs.........30

- Moderate, occasiona............20

- Moderate, continual.............10

- Severe............................ 0

Flexion contracture (if present)

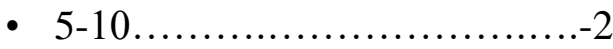

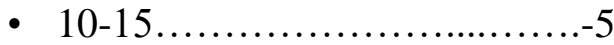

- 16-20.......................... 10

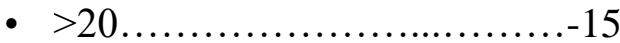

Extension lag

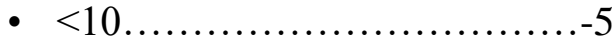

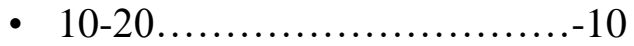

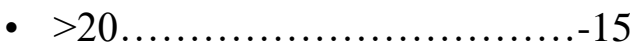

Total ROM

\begin{tabular}{|c|c|c|c|c|c|c|c|c|c|}
\hline ROM & $\begin{array}{c}\text { Points } \\
\text { given }\end{array}$ & ROM & $\begin{array}{c}\text { Points } \\
\text { given }\end{array}$ & ROM & $\begin{array}{c}\text { Points } \\
\text { given }\end{array}$ & ROM & $\begin{array}{c}\text { Pointsgi } \\
\text { ven }\end{array}$ & ROM & $\begin{array}{c}\text { Points } \\
\text { given }\end{array}$ \\
\hline $0-5$ & 1 & $6-10$ & 2 & $11-15$ & 3 & $16-20$ & 4 & $21-25$ & 8 \\
\hline $26-30$ & 6 & $31-35$ & 7 & $36-40$ & 8 & $41-45$ & 9 & $46-50$ & 10 \\
\hline $51-55$ & 11 & $56-60$ & 12 & $61-65$ & 13 & $66-70$ & 14 & $71-75$ & 15 \\
\hline $76-80$ & 16 & $81-85$ & 17 & $86-90$ & 18 & $91-95$ & 19 & $96-100$ & 20 \\
\hline $101-105$ & 21 & $106-110$ & 22 & $111-115$ & 23 & $116-120$ & 24 & $121-125$ & 25 \\
\hline
\end{tabular}

Alignment (varus\& valgus)

- 0 $-15$

$-12$

• 2 .......................... -9

• $3 \ldots \ldots \ldots \ldots \ldots \ldots \ldots \ldots \ldots . . .6$

- 4 ............................ -3

- $5-10$. .0

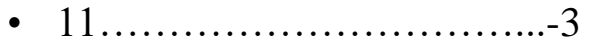

• $12 \ldots \ldots \ldots \ldots \ldots \ldots \ldots \ldots \ldots . . . . . . .6$

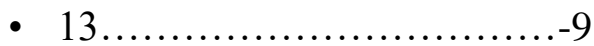

• $14 \ldots \ldots \ldots \ldots \ldots \ldots \ldots \ldots . . . . . . . . . . . .12$

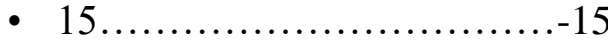

- Over 15..........................-20 
Stability (maximum movement in any position)

- Antero-posterior

- $<5 \mathrm{~mm} \quad 10$

- 5-10mm 5

- $+10 \mathrm{~mm} 0$

- Medio-lateral

- $<5 \quad 15$

- 6-9 10

- 10-14 5

- 150

\section{Grading for the Knee Society Score}

- Excellent 80-100
- Good 70-79

- Fair 60-69

- Poor below 60

\section{Statistical analysis:}

Statistical presentation and analysis of the present study were conducted using the mean and standard Deviation. Unpaired student t-test was used to compare between the two groups in quantitative data. chi-square test was computed for qualitative data and Linear Correlation coefficient was used for detection of correlation between two quantitative variables in one group [r] by SPSS V20. Significant level was at $\leq 0.05$.

\section{RESULTS}

The mean age at presentation was about 40.70 \pm 14.06 years (range: 22-70 years). The study included both sexes: 15 (75\%) were females and $5(25 \%)$ were males (Fig.2). The mode of trauma was road traffic accidents in $15(75 \%)$ cases with 9 cases in group I and 6 cases in group II, while Falling from height in 5 cases $(25 \%)$ with 1 cases in group I and 4 cases in group II. 15 patients $(75 \%)$ had isolated distal femur fractures while with 8 cases in group I and 7 cases in group II (Table 1).

Table(1): Demographic data

\begin{tabular}{|c|c|c|c|c|c|}
\hline Demographic data & Group I & Group II & $\begin{array}{c}\text { Test } \\
\text { value* }^{*}\end{array}$ & P-value & Sig. \\
\hline Age (years) & & & & & \\
\hline Range & $22-70$ & $18-63$ & \multirow{2}{*}{0.213} & \multirow{2}{*}{0.792} & \multirow{2}{*}{ NS } \\
\hline Mean \pm SD & $40.70 \pm 14.06$ & $40.90 \pm 16.05$ & & & \\
\hline Sex & & & & & \\
\hline Male & $1(10 \%)$ & $4(40 \%)$ & \multirow{2}{*}{2.40} & \multirow{2}{*}{0.121} & \multirow{2}{*}{ NS } \\
\hline Female & $9(90 \%)$ & $6(60 \%)$ & & & \\
\hline
\end{tabular}

The type of fracture according to $\mathrm{AO}$ classification of fractures of long bones was type"33". All patients of this study were type $\mathrm{C}$ fracture except one case A2 (Table 2). 
Table (2): Classifications of fractures

\begin{tabular}{|c|c|c|c|c|c|}
\hline \multirow{2}{*}{ Groups } & \multicolumn{2}{|c|}{ Group I } & \multicolumn{2}{c|}{ Group II } & \multirow{2}{*}{ P-value } \\
\cline { 2 - 5 } Classifications & No. & \% & No. & \% & \\
\hline A2 & 1 & $10.0 \%$ & 0 & $0.0 \%$ & \\
\hline C2 & 8 & $80.0 \%$ & 10 & $100.0 \%$ & \multirow{2}{*}{0.329} \\
\hline C3 & 1 & $10.0 \%$ & 0 & $0.0 \%$ & \\
\hline Total & 10 & $100.0 \%$ & 10 & $100.0 \%$ & \\
\hline
\end{tabular}

The mean range of time in weeks till partial weight bearing was allowed in group I was $8.00 \pm 2.31$ ranging from $6 \mathrm{w}$ o $14 \mathrm{w}$, while in group II the mean was
$8.00 \pm 1.63$ with the range from $6 \mathrm{w}$ to $10 \mathrm{w}$. The P-value was 0.962 insignificant differences between two groups (Table 3).

Table (3): Time till Partial weight bearing

\begin{tabular}{|c|c|c|c|c|c|c|c|c|}
\hline \multirow{2}{*}{ Groups } & \multicolumn{6}{|c|}{ Part weight bearing } & \multicolumn{2}{c|}{ T-test } \\
\cline { 2 - 9 } & \multicolumn{3}{|c|}{ Range } & Mean & \pm & SD & T & P-value \\
\hline Group I & 6 & - & 14 & 8.00 & \pm & 2.31 & \multirow{2}{*}{0.007} & \multirow{2}{*}{0.962} \\
\hline Group II & 6 & - & 10 & 8.00 & \pm & 1.63 & & \\
\hline
\end{tabular}

The mean range of time in weeks till full weight bearing was allowed in group I was $14 \pm 3.65 \mathrm{w}$ ranging from $12 \mathrm{w}$ to $24 \mathrm{w}$, while in group II the mean was $15 \pm 2.16 \mathrm{w}$ with the range from $12 \mathrm{w}$ to $18 \mathrm{w}$. The $\mathrm{P}$ value was 0.466 indicating that group I time to full weight bearing is highly significant less than group II (Table 4).

Table (4): Time till Full weight bearing

\begin{tabular}{|c|c|c|c|c|c|c|c|c|}
\hline \multirow{2}{*}{ Groups } & \multicolumn{5}{|c|}{ Full weight bearing } & \multicolumn{2}{c|}{ T-test } \\
\cline { 2 - 8 } & \multicolumn{3}{|c|}{ Range } & Mean & \pm & SD & T & P-value \\
\hline Group I & 12 & - & 24 & 14.00 & \pm & 3.65 & \multirow{2}{*}{0.556} & \multirow{2}{*}{0.466} \\
\hline Group II & 12 & - & 18 & 15.00 & \pm & 2.16 & & \\
\hline
\end{tabular}

The mean range of time in weeks till radiological healing group I was $15.60 \pm 2.46 \mathrm{w}$ ranging from $12 \mathrm{w}$ to $20 \mathrm{w}$, while in group II the mean was

Table (5): Time till radiological healing

\begin{tabular}{|c|c|c|c|c|c|c|c|c|}
\hline \multirow{2}{*}{ Groups } & \multicolumn{6}{|c|}{ Healing } & \multicolumn{2}{c|}{ T-test } \\
\cline { 2 - 9 } & \multicolumn{3}{|c|}{ Range } & Mean & \pm & SD & T & P-value \\
\hline Group I & 12 & - & 20 & 15.60 & \pm & 2.46 & \multirow{2}{*}{1.386} & \multirow{2}{*}{0.291} \\
\hline Group II & 10 & - & 16 & 13.80 & \pm & 1.93 & & \\
\hline
\end{tabular}

The mean total ROM in group I was $98.20 \pm 4.94$, while in group II was 104.50 \pm 6.77 . The P-value was 0.217 insignificant differences between two groups (Table 6).
$13.80 \pm 1.93 \mathrm{w}$ with the range from $10 \mathrm{w}$ to $16 \mathrm{w}$. The P-value was 0.291 insignificant differences between two groups (Table 5). 
AHMED ABD EL-NOOR SAAD et al.,

Table (6): Total ROM

\begin{tabular}{|c|c|c|c|c|c|c|c|c|}
\hline \multirow{2}{*}{ Groups } & \multicolumn{5}{|c|}{ Flexion Rom } & \multicolumn{2}{c|}{ T-test } \\
\cline { 2 - 9 } & \multicolumn{3}{|c|}{ Range } & Mean & \pm & SD & t & P-value \\
\hline Group I & 90 & - & 106 & 98.20 & \pm & 4.94 & \multirow{2}{*}{1.053} & \multirow{2}{*}{0.217} \\
\hline Group II & 100 & - & 125 & 104.50 & \pm & 6.77 & & \\
\hline
\end{tabular}

$60 \%$ of all patients experienced mild occasional pain after union and during follow up period (Table 7).

Table (7): Pain

\begin{tabular}{|l|c|c|c|c|c|c|}
\hline \multirow{2}{*}{ Pain } & \multicolumn{9}{|c|}{ Groups } \\
\cline { 2 - 8 } & \multicolumn{2}{|c|}{ Group I } & \multicolumn{2}{c|}{ Group II } & \multicolumn{2}{c|}{ Total } \\
\cline { 2 - 8 } & $\mathbf{N}$ & $\mathbf{\%}$ & $\mathbf{N}$ & $\mathbf{\%}$ & $\mathbf{N}$ & $\mathbf{\%}$ \\
\hline Mild Walking and Stairs & 1 & $10.0 \%$ & 1 & $10.0 \%$ & 2 & $10.0 \%$ \\
\hline Mild Occasional & 5 & $50.0 \%$ & 7 & $70.0 \%$ & 12 & $60.0 \%$ \\
\hline Mod Occasional & 1 & $10.0 \%$ & 0 & $0.0 \%$ & 1 & $5.0 \%$ \\
\hline None & 3 & $30.0 \%$ & 2 & $20.0 \%$ & 5 & $25.0 \%$ \\
\hline Total & 10 & $100.0 \%$ & 10 & $100.0 \%$ & 20 & $100.0 \%$ \\
\hline \multirow{2}{*}{ Chi-square } & \multicolumn{7}{|c|}{2.291} \\
\cline { 2 - 7 } & $\mathrm{X}^{2}$ & \multicolumn{7}{|c|}{0.682} \\
\cline { 2 - 8 } & P-value & \multicolumn{7}{|c|}{} \\
\hline
\end{tabular}

No significant difference between the 2 groups regarding stability or alignment (Table 8).

Table (8): Alignment, A-P stability and medial lateral stability

\begin{tabular}{|c|c|c|c|c|c|c|c|c|}
\hline \multirow{3}{*}{ Parameters } & \multirow{2}{*}{\multicolumn{2}{|c|}{ Group I }} & \multirow{2}{*}{\multicolumn{2}{|c|}{ Group II }} & \multirow{2}{*}{\multicolumn{2}{|c|}{ Total }} & \multirow{2}{*}{\multicolumn{2}{|c|}{ Chi-square }} \\
\hline & & & & & & & & \\
\hline & $\mathbf{N}$ & $\%$ & $\mathbf{N}$ & $\%$ & $\mathbf{N}$ & $\%$ & $x^{2}$ & P-value \\
\hline \multicolumn{9}{|c|}{ Flexion contracture } \\
\hline $5-10$ & 8 & $80 \%$ & 6 & $60 \%$ & 14 & $70 \%$ & \multirow{2}{*}{0.952} & \multirow{2}{*}{0.329} \\
\hline $10-15$ & 2 & $20 \%$ & 4 & $40 \%$ & 6 & $30 \%$ & & \\
\hline \multicolumn{9}{|l|}{\begin{tabular}{|l|} 
Extensor lag \\
\end{tabular}} \\
\hline$<10$ & 7 & $70 \%$ & 6 & $60 \%$ & 13 & $65 \%$ & \multirow{2}{*}{0.220} & \multirow{2}{*}{0.639} \\
\hline $10-20$ & 3 & $30 \%$ & 4 & $40 \%$ & 7 & $35 \%$ & & \\
\hline \multicolumn{9}{|l|}{ Alignment } \\
\hline $5=10$ & 7 & $70.0 \%$ & 8 & $80.0 \%$ & 15 & $75.0 \%$ & \multirow{4}{*}{2.400} & \multirow{4}{*}{0.494} \\
\hline 15 varus & 1 & $10.0 \%$ & 2 & $20.0 \%$ & 3 & $15.0 \%$ & & \\
\hline 15 valgus & 1 & $10.0 \%$ & 0 & $0.0 \%$ & 1 & $5.0 \%$ & & \\
\hline $5=20$ & 1 & $10.0 \%$ & 0 & $0.0 \%$ & 1 & $5.0 \%$ & & \\
\hline \multicolumn{9}{|l|}{ Ant. Posterior } \\
\hline$<5 \mathrm{~mm}$ & 10 & 100.0 & 10 & 100.0 & 20 & 100.0 & \multirow{2}{*}{0.000} & \multirow{2}{*}{1.000} \\
\hline $5-10$ & 0 & 0.00 & 0 & 0.00 & 0 & 0.00 & & \\
\hline \multicolumn{9}{|l|}{ Medial lateral } \\
\hline$<5$ & 10 & 100.0 & 10 & 100.0 & 20 & 100.0 & \multirow{2}{*}{0.000} & \multirow{2}{*}{1.000} \\
\hline $10-14$ & 0 & 0.00 & 0 & 0.00 & 0 & 0.00 & & \\
\hline
\end{tabular}


The overall knee society score showed no significant difference between the 2 groups. The mean for group I was
$75.90 \pm 6.06$ and for group II was $78.80 \pm 10.67$ (Table 9).

Table (9): Knee society score grading

\begin{tabular}{|l|c|c|c|c|c|c|}
\hline \multirow{2}{*}{ Knee society score } & Groups & \multicolumn{2}{|c|}{ Group I } & \multicolumn{2}{c|}{ Group II } & \multicolumn{2}{c|}{ Total } \\
\cline { 2 - 7 } & $\mathbf{N}$ & $\mathbf{\%}$ & $\mathbf{N}$ & $\mathbf{\%}$ & $\mathbf{N}$ & $\%$ \\
\cline { 2 - 7 } & 0 & $0 \%$ & 1 & $10 \%$ & 1 & $5 \%$ \\
\hline Poor & 2 & $20 \%$ & 0 & $0 \%$ & 2 & $10 \%$ \\
\hline Fair & 4 & $40 \%$ & 3 & $30 \%$ & 7 & $35 \%$ \\
\hline Good & 4 & $40 \%$ & 6 & $60 \%$ & 10 & $50 \%$ \\
\hline Excellent & 10 & $100 \%$ & 10 & $100 \%$ & 20 & $100 \%$ \\
\hline Total & \multicolumn{7}{|c|}{0.465} \\
\hline Mean \pm SD & $75.90 \pm 6.06$ & \multicolumn{7}{|c|}{$78.80 \pm 10.67$} \\
\hline P-value & \multicolumn{7}{|c|}{} \\
\hline
\end{tabular}

Negative correlation between age and knee society score with part weight bearing, full weight bearing when $\mathrm{P}$-value was $<0.05$ and $\mathrm{R}$ was $(-0.514,-0.535$, -
0.485). Positive correlation between age and knee society score, the younger the age the better knee society score (Table 10).

Table (10): Correlation between Knee society score and others items

\begin{tabular}{|l|c|c|}
\hline \multirow{2}{*}{ Karameters } & \multicolumn{2}{|c|}{} \\
\cline { 2 - 3 } & R & P-value \\
\hline Age & -0.205 & 0.186 \\
\hline Partial weight bearing & -0.514 & $<0.001^{* *}$ \\
\hline Healing & -0.535 & $<0.001^{* *}$ \\
\hline Full weight bearing & -0.485 & $0.006^{*}$ \\
\hline
\end{tabular}

Negative correlation between age and knee society score with part weight bearing, full weight bearing when $\mathrm{P}$-value was $<0.05$ and $\mathrm{R}$ was $(-0.514,-0.535$, 0.485). Positive correlation between age and knee society score, the younger the age the better knee society score.
Overall complications in group I was $20 \%$ while in group II was $30 \%$ with the P-value of 0.547 which indicates non significance of complication rete between the 2 groups (Table 11).

\section{Table (11): Complications}

\begin{tabular}{|c|c|c|c|c|c|c|}
\hline \multirow{2}{*}{ Complication } & \multicolumn{2}{|c|}{ Group I } & \multicolumn{2}{c|}{ Group II } & \multicolumn{2}{c|}{ Total } \\
\cline { 2 - 7 } & $\mathbf{N}$ & $\mathbf{\%}$ & $\mathbf{N}$ & $\mathbf{\%}$ & $\mathbf{N}$ & $\mathbf{\%}$ \\
\hline No & 8 & $80.0 \%$ & 7 & $70.0 \%$ & 15 & $75.0 \%$ \\
\hline DVT & 1 & $10.0 \%$ & 1 & $10.0 \%$ & 2 & $10.0 \%$ \\
\hline $\begin{array}{c}\text { Failure Revision through } \\
\text { Double Plating }\end{array}$ & 1 & $10.0 \%$ & 0 & $0.0 \%$ & 1 & $5.0 \%$ \\
\hline Medial plate infection & 0 & $0.0 \%$ & 1 & $10.0 \%$ & 1 & $5.0 \%$ \\
\hline Superficial wound infection & 0 & $0.0 \%$ & 1 & $10.0 \%$ & 1 & $5.0 \%$ \\
\hline Total & 10 & $100.0 \%$ & 10 & $100.0 \%$ & 20 & $100.0 \%$ \\
\hline Chi-square & \multicolumn{7}{|c|}{3.067} \\
\hline
\end{tabular}




\section{DISCUSSION}

In our clinical study we managed 20 cases with distal femoral fractures $\mathrm{AO}$ classification type A2, A3, C2 or C3. 10 cases were surgically managed by open reduction internal fixation through single lateral plate, 10 cases were surgically managed by open reduction internal fixation through double plating technique. 18 cases were AO C2 while 1 case was $\mathrm{AO} \mathrm{C} 3$ and 1 case A2.

The purpose of this study was to assess the clinical results, time to union and complications of 2 groups of patients with distal metaphyseal femoral fractures.

The most important finding in this study was the overall satisfactory outcome of the both methods and paucity of severe complications in both groups. In group I, 4 cases $(40 \%)$ had good results, 2 cases (10\%) had fair results while 0 cases $(0 \%)$ had poor results. In group II, 6 cases (60\%) had excellent results, 3 cases $(30 \%)$ had good results, 0 cases $(0 \%)$ had fair results while 1 case $(10 \%)$ had poor results. The overall knee society score showed no significant difference between the 2 groups. The follow up period for the cases range from (8-24) weeks and with the mean $(14.56 \pm 4.85)$ weeks. Several studies reported that double plating is an advantageous solution for Type C3 distal femoral fractures (Khalil et al., 2012).

Our clinical study showed that the fractures became united within 12 weeks. One patient (10\%) from group II experienced lateral wound superficial infection in the form of erythema and serous discharge 1 week post-operative. It was controlled by daily dressing with antibiotics. One case of group II (10\%) developed DVT another one case of group
I (10\%), although being on prophylactic anticoagulant. Vascular consultation was done and therapeutic dose of anticoagulant then was initiated. 1 case (10\%) in group II developed medial plate infection and medial wound dehiscence 3 weeks after the operation. The plate was $\mathrm{T}$ buttress and the patient was so skinny, so that revision of the medial plate was done by a reconstruction plate. One case $(10 \%)$ of group I needed revision after 3 months due to plate failure with screw pull out. This may be due to technical error of too much lower positioning of the lateral plate during surgery and had medial metaphyseal communication. Revision was done by double plating technique. Chronic pain may be due to superficial cutaneous nerves damage, the development of scar tissue, or an aggravation of underlying arthritis. Most of the published studies on lateral locking plates reported a union rate ranging between 81\%-95\% (Meneghini et al., 2014, Ricci et al., 2014 and Rodriguez et al., 2014), The union rate for patients treated by retrograde nails was reported to be $91 \%$ (Meneghini et al., 2014). Complications related to the implants, such as loosening, breakage, and rotational malposition, were reported as being between $5 \%$ to $7 \%$, with a revision rate ranging between $19 \%$ to $23 \%$ (Ricci et al., 2014 and Rodriguez et al., 2014). Other potential complications, such as hardware malposition and plate located too ventral, too proximal or too short for adequate fixation (Ricci et al., 2014), may weaken mechanical stability of the implant followed by early loosening and failure. The double-plating technique may overcome these complications by its properties that provide increased stability 
by compensating for some of the intraoperative technical errors to permit complete healing.

Khalil and Ayoub (2012) used a double-plating technique through a modified Olerud extensile approach where the mean radiologic healing time was reported to be 18.3 weeks.

A potential vascular injury to the distal part of the medial thigh and femur aspects may be expected during the procedure. Computerized tomographic angiography studies demonstrated that this area was supplied by two vessels, the medial superior genicular artery and the third perforating artery to the vastus medialis muscle. However, neither artery is adjacent to the bone, so vessel injury can be prevented by meticulous dissection.

Limitations of this study included its retrospective nature, and the relative small group of patients studied. The treatment of all patients by senior surgeons and in two institutions represented strengths of this work.

\section{CONCLUSION}

Although both lateral and Double plating fixation using dual approach for type $\mathrm{C} 2$ and $\mathrm{C} 3$ distal femoral fractures were efficient and safe methods of management, double plating recommended in these cases (medial supracondylar bone loss, low trans condylar bicondylar fractures, medial Hoffa fracture, periprosthetic distal femur fractures, non-union after failed fixation with single lateral plate, poor bone quality and comminuted distal femur fractures C3).

\section{REFERENCES}

1. Elose $R$, cEeccotti $A A$ and Larsen $P$ (2018): Population-based epidemiology and incidence of distal femur fractures. International orthopedics. Jan 1; 42 (1):191-6.

2. Gwathmey FW JR, Jones-Quaidoo SM and Kahler D (2010): Dislat femoral fractures: current concepts. J Am Acad Orthop Surg; 18:597-607.

3. Henderson CE, Kuhl LL and Fitzpatrick DC (2011): locking plates for distal femur fractures: is there a problem with fracture healing $\mathrm{J}$ Orthop Traumatol .,25:S8-S14.

\section{Imam MA, Torieh A and Matthana} A (2018): Double plating of intraarticular multi fragmentary C3-type distal femoral fractures through the anterior approach. Eur J Orthop Surg Traumatol., 28(1):121-30.

5. Khalil Ael S and Ayoub MA (2012): Highly unstable complex C3-type distal femur fracture: can double plating via a modified Olerud extensile approach be a standby solution? J Orthop Traumatol .,13(4):179-88.

6. Meinberg EG, Agel J, Robert CS, Karam MD and Kellam JF (2018): Fracture and Dislocation Classification Compendium_2018. Journal of orthopedic Trauma, 32:s1-10.

7. Meneghini RM, Keyes BJ, Reddy KK and Maar DC (2014): Modern retrograde intramedullary nails versus periarticular locked plates for supracondylar femur fractures after total knee arthroplasty. J Arthroplasty; 29: 1503-6. 
8. Ricci WM, Streubel PN, Morshed S, Collinge CA, Nork SE and Gardner MJ (2014): Risk factors for failure of locked plate fixation of distal. femur fractures: an analysis of 335 Cases. J Orthop Trauma; 28:83-9.

9. Rodriguez EK, Boulton C, Weaver MJ, Herder LM, Morgan JH and Chacko AT (2014): Predictive factors of distal femoral fracture nonunion after lateral locked plating: a retrospective multicenter case-control study of 283 fractures. Injury, 45:5549.
10. Steinberg El, Elis J, Steinberg Y, Salai $M$ and Ben-Tov T (2017): A double-plating approach to distal femur fracture: A clinical study. Injury, 48(10):2260-5.

11.Zhang J, Wei Y, Yin W, Shen and Cao S (2018): Biomechanical and clinical comparison of single lateral plate and double plating of comminuted supracondylar femoral fractures. Acta orthopaedical Belgica., 84: $141-8$. 
مقارنة بين التثبيت بو اسطه شريحة خارجية و شريحتين داخلية و خارجية للكسور المفتتة فوق لقمة عظمة الفخذ أحمد محمد عبدالنور سعد، أحمد عبد الحميد شما، محمد على المرغنى قسم جراحة العظام، كلية الطب، جامعة الأزهر

E-mail: ahmed.elfiky33@yahoo.com

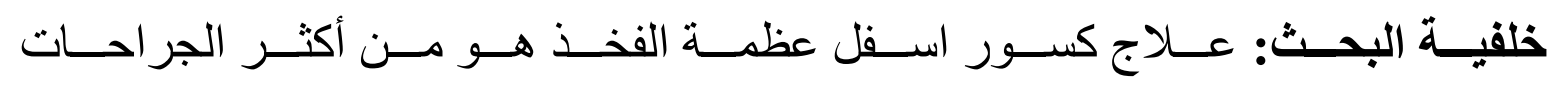

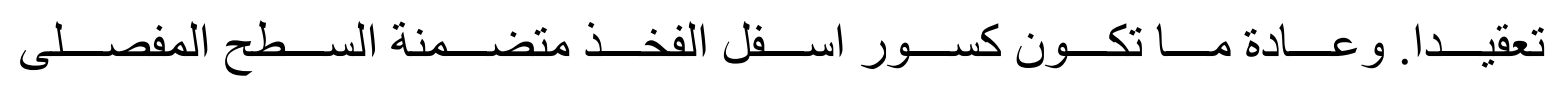

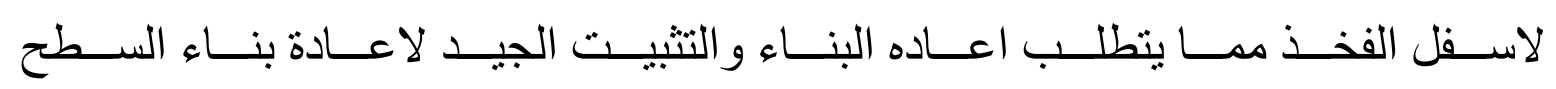

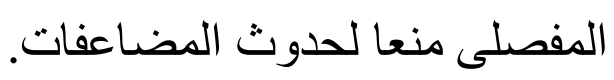

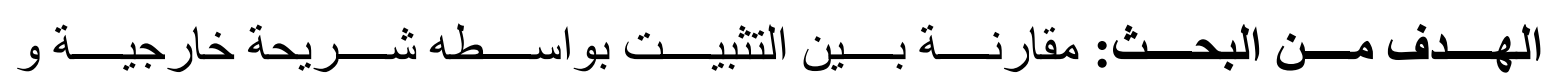
شريحتين داخلية و خارجية للكسور المفتتة فوق لقمة عظمة الفخذ الفئ

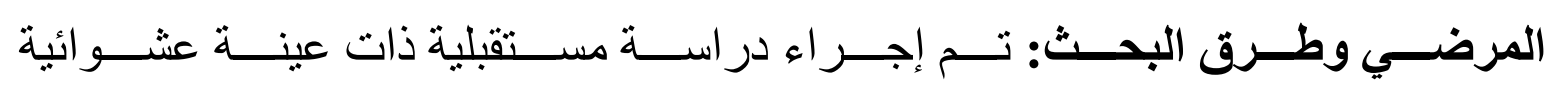

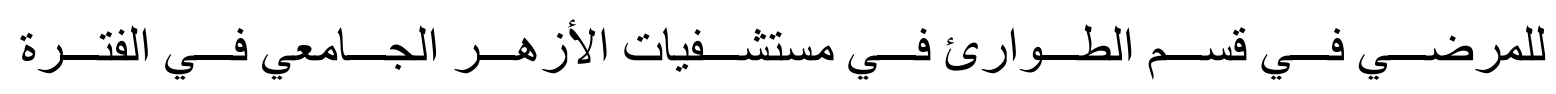

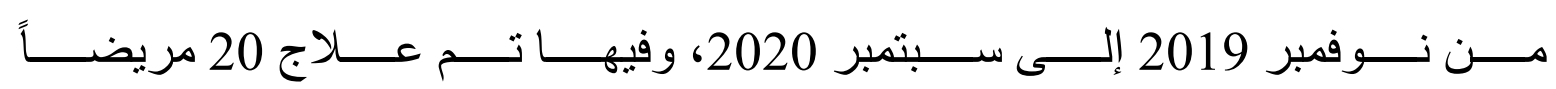

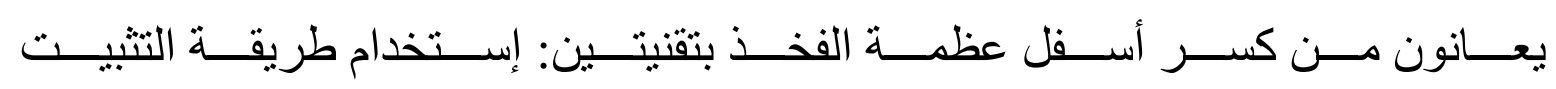

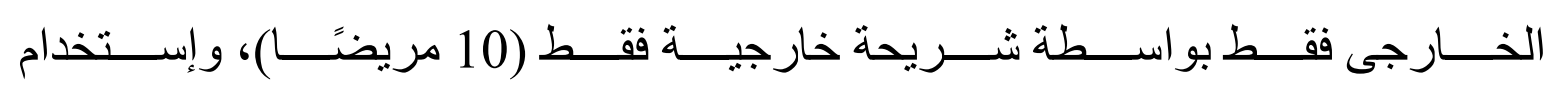

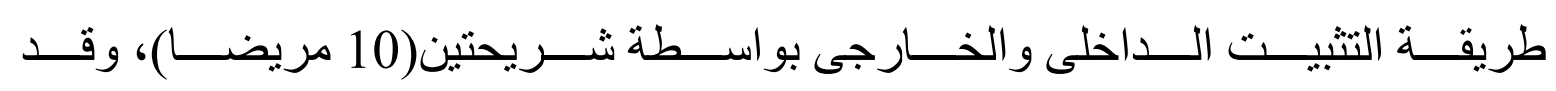
تم تقييم النتائج بو اسطة مجال الحركة للركبة.

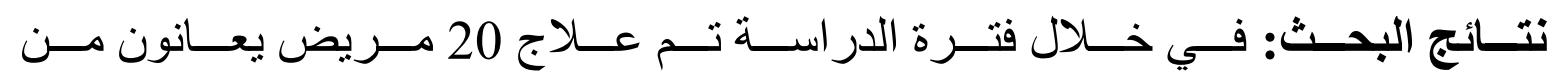

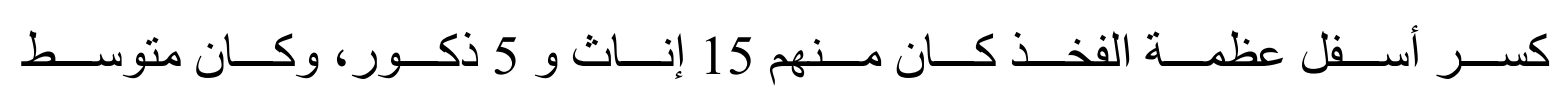

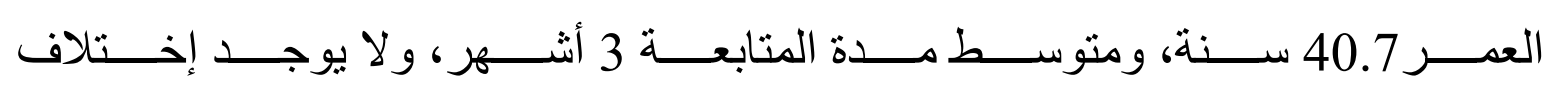

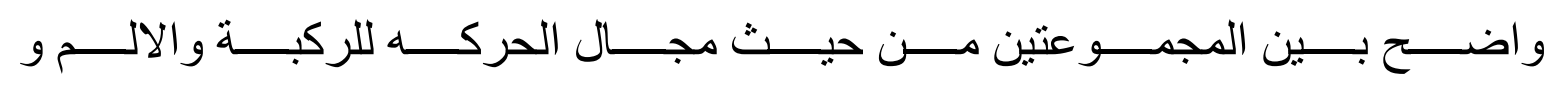

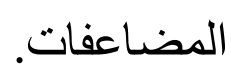




\section{AHMED ABD EL-NOOR SAAD et al.,}

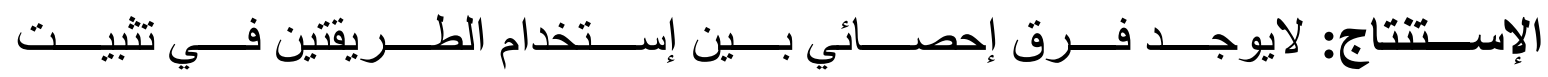

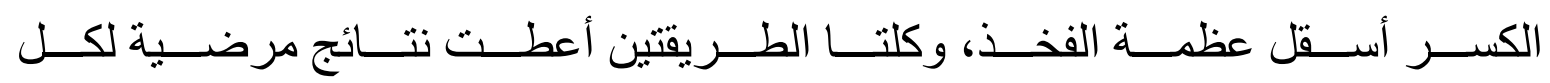

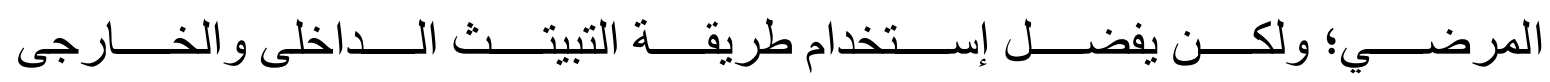

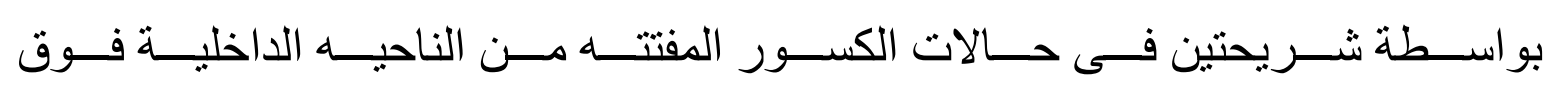

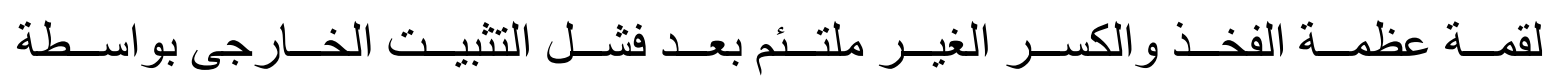

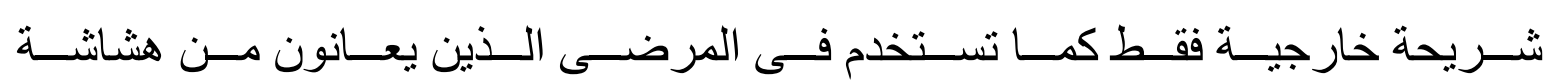

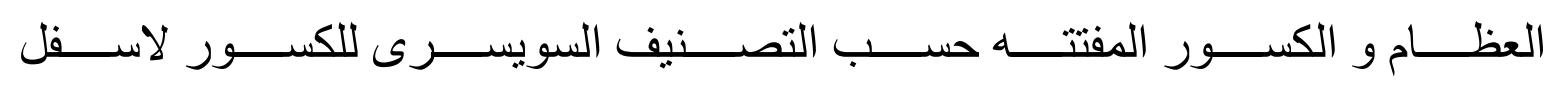

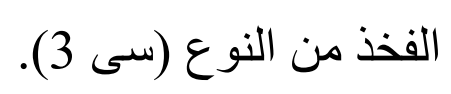

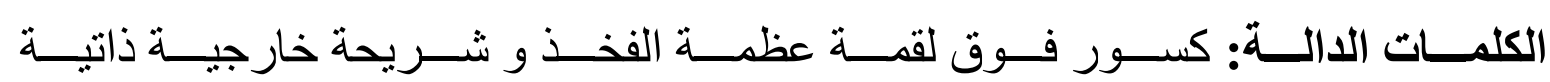
الغلق و شريحتين جانبيتين. 